\title{
"Vazanteiros em movimento": o processo de ambientalização de suas lutas territoriais no contexto das políticas de modernização ecológica
}

\author{
"Vazanteiros' in motion": the process of "environmentalization" \\ of their territorial fights in the context of ecological modernization \\ policies
}

${ }^{1}$ Departamento de Saúde Mental e Coletiva, Faculdade de Medicina, Universidade Estadual de Montes Claros. R. Rui Braga s/n, Vila Mauricéia. 39.401-089 Montes Claros MG Brasil.

felisaanaya@gmail.com

\begin{abstract}
This text presents the process of environmentalization of the social campaigns of Pau Preto, Pau de Légua and Quilombo da Lapinha in the north of the State of Minas Gerais that culminated in their being re-named as "Vazanteiros' in Motion." The analysis of the territorial environmental conflict examines it from the perspective of Political Ecology and Critical Sociology. Documents from public environmental and judicial institutions were analyzed as well as meeting and research reports referring to the process of social mobilization and political formation of the " $\mathrm{Va}$ zanteiros in Motion." Ethnographic fieldwork was conducted from 2006 to 2012 and the different actors involved in the conflict were interviewed. The "extended-case method" or "situational analyses" were also used in order to demonstrate the ethnographic social events from a procedural and historical perspective. The results revealed the contradictions in sustainable development ideology, which made it possible to consolidate the agribusiness in that region through the creation of parks for irrigated fruit production projects as an environmental compensation strategy and the emergence of an important social movement of territorial claims in the environmental field.
\end{abstract}

Key words Environment, Conflict, Territory, Traditional people and communities
Resumo Este texto tem como objetivo apresentar o processo de ambientalização das lutas sociais das comunidades de Pau Preto, Pau de Légua e Quilombo da Lapinha, no Norte de Minas Gerais, que as ressignificaram nos "Vazanteiros em Movimento", além da análise do conflito ambiental territorial, parte da perspectiva da Ecologia Política e da Sociologia Crítica. Foram analisados documentos de instituições públicas ambientais e jurídicas, atas e relatórios de pesquisas referentes ao processo de mobilização social e formação política dos "Vazanteiros em Movimento". Foi realizado trabalho de campo etnográfico no período de 2006 à 2012, entrevistas com os distintos atores envolvidos no conflito e a utilização do "extended-case method" (método de estudo de caso detalhado) ou "análise situacional", com o objetivo de demonstrar os eventos sociais etnografados em sua perspectiva processual e histórica. Os resultados revelam as contradições da ideologia do desenvolvimento sustentável, que possibilitou a consolidação do agronegócio na região, através dos parques compensatórios ao projeto de fruticultura irrigada e a emergência de um importante movimento social de reivindicação territorial no campo ambiental. Palavras-chave Ambiente, Conflito, Território, Povos e comunidades tradicionais 


\section{Introdução}

$\mathrm{Na}$ região Norte de Minas Gerais, ao longo da baixada média do rio São Francisco, existe atualmente um movimento social e político de reivindicação territorial que envolve as comunidades tradicionais vazanteiras de Pau Preto, Pau de Légua e Quilombo da Lapinha. Localizadas nos municípios de Matias Cardoso e Manga, estes distintos grupos sociais se articularam em consequência à sobreposição dos parques estaduais Verde Grande (1998), Lagoa do Cajueiro (1998) e Mata Seca (2001) às suas terras tradicionalmente ocupadas. Criados como medidas compensatórias ao projeto de fruticultura irrigada Jaíba, tais parques, serviram funcionalmente para a expansão da etapa 2 deste projeto, consolidando, assim, o agronegócio na região. Será, porém, em 2005, com a valorização dos remanescentes de matas secas do Jaíba, pelo Atlas da Biodiversidade de Minas Gerais (BIODIVERSITAS) ${ }^{1}$, que a região passou a ser considerada como área prioritária para conservação, ratificando a existência desses parques e a necessidade de sua efetivação enquanto unidades de proteção integral. Conjuntura que desencadeou um processo de restrições às práticas tradicionais vazanteiras e sua expropriação por parte dos agentes ambientais do Instituto Estadual de Florestas (IEF), responsáveis pelo gerenciamento e fiscalização das unidades de conservação estaduais. Tal situação social, impôs outra dinâmica territorial a essas comunidades, que unificaram-se na luta pela reapropriação de seus territórios ancestrais, através do "Movimento dos Encurralados pelos Parques”. Ao longo desta articulação, outras comunidades vazanteiras da baixada média sanfranciscana, mobilizadas pela revitalização do rio São Francisco e encurraladas por distintos projetos desenvolvimentistas, incorporaram-se a esse movimento social. Assim, a denúncia do encurralamento foi substituída por uma série de ações coletivas no campo ambiental e o "Movimento dos Encurralados pelos Parques" ressignificado para "Vazanteiros em Movimento". Fruto do reconhecimento identitário e cultural desses grupos e do processo de "ambientalização"2 de suas lutas territoriais.

\section{"Encurralamento" e o "Sistema vazanteiro" de resistência}

Historicamente, o "encurralamento" diz respeito a uma expressão nativa utilizada no Norte de Minas Gerais, para se referir a uma sobreposição de territorialidades ao longo da bacia do alto e médio São Francisco. Sobreposição que se iniciou com a ocupação e o povoamento da região por bandeirantes baianos e paulistas, através da implementação de grandes fazendas de gado às margens deste rio no período colonial. Tal ocupação se intensificou, em meados dos anos 1930/40, com a derrubada das matas secas nativas da região por ocasião da construção da estrada de ferro que orientou novas relações comerciais com Rio de Janeiro, Belo Horizonte e São Paulo. A regularização fundiária nesse período trouxe um novo ordenamento territorial que provocou a expropriação de diversos grupos sociais que mantinham formas de apropriação coletiva do ambiente e a constituição de conflitos fundiários com grandes fazendeiros, que os confinava nos interstícios de suas fazendas ou em áreas distantes. Tais conflitos se acentuaram, nos anos 1960/70, com as primeiras iniciativas governamentais de ocupação planejada da área do Jaíba, quando implementadas políticas voltadas para a industrialização e a modernização do campo. Período de grandes incentivos fiscais subsidiados pela Superintendência de Desenvolvimento do Nordeste (Sudene) e da regularização fundiária realizada pela Fundação Rural Mineira (Ruralminas), principais mecanismos políticos de concentração de renda e grilagem de terra na região, beneficiando grandes empresas e latifundiários de São Paulo, Montes Claros e arredores. Em meados dos anos 1990, comunidades geraizeiras do Alto Rio Pardo, "encurraladas" por grandes maciços de eucalipto, deram-se conta da condição de "atingidos" e objetivaram suas lutas pela reapropriação territorial no "Movimento dos Encurralados". Contexto em que o "encurralamento" assume conotação política de denúncia e de resistência, incorporando outros povos e comunidades tradicionais da região, tal como remanescentes de quilombos, catingueiros e vazanteiros. Constituiu-se uma rede social, análoga aos "movimentos de territorialização"3, que reivindicavam o reconhecimento de suas diferenças culturais e ecológicas vinculadas à defesa de seus territórios. Articulados no Fórum de Desenvolvimento Sustentável do Norte de Minas, este era composto pelo Centro de Agricultura Alternativa do Norte de Minas (CAA), Comissão Pastoral da Terra (CPT), Cáritas Brasileira, Federação dos Trabalhadores da Agricultura do Estado de Minas Gerais (FETAEMG), Central Única de Trabalhadores (CUT), Sindicatos de Trabalhadores Rurais, Associação para a Barca Andar, Articulação do Semiárido (ASA) e a Rede Alerta contra o Deserto Verde. Fórum que se constituiu em es- 
paço de interlocução e formação política desses grupos, apresentando críticas sobre o tipo de desenvolvimento implementado na região e associadas ao pensamento socioambientalista emergente. Neste espaço, a conservação do ambiente se constituiu como referência fundamental na luta pelo território, e a relação dialética dessas comunidades tradicionais com a natureza serviu como fator de distinção identitária entre elas e os demais grupos camponeses. Emergem daí: os geraizeiros da Serra Geral "encurralados" pela monocultura de eucalipto; os quilombos de Brejo dos Crioulos e Gurutubanos, "encurralados” por grandes empresas rurais e projetos de irrigação; e as comunidades vazanteiras de Pau Preto, Pau de Légua e Quilombo da Lapinha, “encurraladas” atualmente pelos parques estaduais compensatórios ao projeto de fruticultura irrigada Jaíba.

Porém, a especificidade das lutas territoriais das comunidades vazanteiras de Pau Preto, Pau de Légua e Quilombo da Lapinha, em relação aos demais grupos "encurralados”, é que, ao serem atingidas por unidades de conservação integral, suas reivindicações territoriais foram se construindo no campo ambiental. Campo compreendido como o espaço social e político da praxis ecológica, lugar institucionalizado do debate ambiental, com regras e legislação próprias. Assim, a sobreposição dos parques aos territórios tradicionais das comunidades vazanteiras de Pau Preto, Pau de Légua e Quilombo da Lapinha reforçou o processo de "encurralamento" por grandes empresas rurais e o projeto Jaíba, na década de 1960/70, que os expropriou das terras-firmes e os confinou nas ilhas e barrancos do rio São Francisco. Contexto que teve como consequência a intensificação da prática da vazante e a conversão das ilhas e beira-rio, até então não habitadas, em locais de trabalho e morada. Frente ao "encurralamento", várias estratégias defensivas e cotidianas foram utilizadas por estes grupos vazanteiros para manterem minimamente parte de seus territórios. Pois, além de serem obrigados a migrarem para as ilhas, muitos foram também, em direção às periferias de cidades como Manga e Matias Cardoso, criando um sistema próprio, mesmo que precário e temporário, de manterem o vínculo com o território expropriado:

A maioria de nós vazanteiros fomos expulsos pelos fazendeiros. A maioria dos tradicionais aqui tem o problema de ficar na cidade e na ilha. Quase todos têm casinha na cidade porque não pode mais ficar na beira do rio, que o fazendeiro cria problema. Mas quando o rio baixa, a gente volta. Esse é o sistema vazanteiro. (Depoimento vazanteiro na Ilha de jenipapo - V Encontro "Vazanteiros em Movimento" - Itacarambi, 2010) 4 .

Assim, o "sistema vazanteiro" constituiu-se em um modo de defesa territorial análogo ao que Scott ${ }^{5}$ identificou em seus estudos sobre grupos camponeses indianos como "resistência silenciosa" ou "arma dos fracos". Ou seja, o vínculo com o território expropriado é mantido através da prática de pequenos atos de insubordinação, sem confronto direto, garantindo assim, a segurança dos praticantes pelo anonimato. A partir desta perspectiva, o "sistema vazanteiro" pode ser compreendido como parte intrínseca da territorialidade destes grupos que mantêm uma relação identitária com o rio São Francisco e seus ciclos. Pois, observa-se que as cheias e as baixas deste rio se constituem como oportunidades específicas de reterritorialização, utilizadas pelos vazanteiros até mesmo em períodos de perdas materiais ocasionadas por grandes enchentes.

Não havia moradia na ilha até a expulsão da gente pelos fazendeiros que grilaram nossas terras. Depois que a gente foi ficando por ali. Pois, como a gente tinha sido expulsos para a 'rua' (cidade), fomos voltando pelas ilhas. Aproveitamos a boa vontade do rio e fomos voltando. (Entrevista concedida por vazanteiro da Comunidade de Pau Preto - agosto de 2010) ${ }^{4}$.

Nesse sentido, o rio São Francisco, dotado de volição, sempre operou como fator de identificação e de defesa de um território produzido pela mobilidade natural de suas enchentes e vazantes. O que faz dele um parceiro dos grupos vazanteiros, que deve ser respeitado em suas próprias decisões, pois, ao mesmo tempo que as enchentes "tomam" as moradias dos vazanteiros, por outro lado, sempre trazem a possibilidade de um retorno à terra-firme. Retorno que se dá também através de uma série de incursões sorrateiras ao território expropriado, para visitação a lugares simbólicos, extração de plantas medicinais e idas às lagoas para pescar ou somente olhar, "só para matar a saudade" (Entrevista concedida por vazanteiro da Comunidade de Pau de Légua - outubro de 2010) ${ }^{4}$. Elemento fundamental desse "sistema vazanteiro", o rio São Francisco se constitui em aliado, a "arma dos fracos", que propiciou a associação e o reconhecimento dos vazanteiros como os "povos das águas e das terras crescentes".

No final dos anos 1990 e meados dos anos 2000, a situação social de "encurralamento" vivenciada pelos vazanteiros foi redefinida pelo novo contexto de políticas ambientais implementadas na região. Políticas que deram prosseguimento ao processo de desterritorialização 
desses grupos, através da operacionalização das Unidades de Proteção Integral (UPI) compensatórias ao projeto de Fruticultura Irrigada Jaíba. A valorização destas áreas remanescentes de Matas Secas pelo Atlas da Biodiversidade de Minas Gerais impeliu o IEF/MG, responsável pela criação, execução e fiscalização das unidades de conservação do Jaíba e o Instituto Brasileiro de Proteção ao Meio Ambiente (IBAMA), a assumirem ações de vigilância e controle sobre as comunidades vazanteiras. Deu-se início a uma série de proibições e penalizações sobre as práticas extrativistas, de caça, plantio e pesca que fazem parte da cultura vazanteira, redefinindo atores e projetos sociais em conflito, pois, se antes era o fazendeiro (o algoz), hoje é o IEF (Entrevista concedida por vazanteiro da Comunidade de Pau Preto - agosto de 2010) $)^{4}$.

A partir desta conjuntura, no ano de 2005, as comunidades vazanteiras do Quilombo da Lapinha, Pau Preto e Pau de Légua, ao se darem conta da condição de atingidos pelos parques, buscaram na CPT e no CAA apoio para a permanência em seus territórios. Vários encontros de articulação interna e externa destas comunidades foram realizados, constituindo o "movimento dos encurralados pelos parques” e dando início a um processo de ambientalização de suas lutas territoriais.

\section{De "Movimento dos encurralados pelos parques" a "Vazanteiros em movimento"}

Em 2005, foi realizado na Ilha da Ingazeira, entre os municípios de Manga (MG) e Carinhanha (BA), o Primeiro Encontro Interestadual de Homens e Mulheres Vazanteiros do São Francisco. Deste evento foi tributária a Carta Manifesto das Mulheres e Homens Vazanteiros: povos das águas e das terras crescentes do São Francisco ${ }^{6}$, endereçada à sociedade em geral, que se tornou um dos primeiros documentos de visibilização do modo de vida vazanteiro e de suas lutas territoriais. A linguagem técnica-ambiental, trazida pela tradução dos mediadores, aparece incorporada ao vocabulário vazanteiro, que se reconhecem na categoria de "populações tradicionais", presente no decreto do Sistema Nacional de Unidades de Preservação (SNUC) ${ }^{7}$. Categoria que os possibilitou se afirmarem enquanto grupos culturalmente diferenciados, portadores de práticas e saberes tradicionais repassados ao longo de gerações.

No ano de 2006, o Quilombo da Lapinha ocupou a sede da Fazenda Casa Grande, uma das Fazendas Reunidas Vale do São Francisco (FARE-
VASF), localizada no entorno do Parque Estadual Lagoa do Cajueiro e apresentou junto ao INCRA a Proposta de Assentamento Agroextrativista São Francisco: uma contribuição do CAA/NM e da CPT aos vazanteiros da Ilha da Ressaca ${ }^{8}$. Documento em que a complexidade da identidade do grupo emerge, ao autoidentificarem-se enquanto remanescentes de quilombo e comunidade tradicional vazanteira, consubstanciada por suas práticas produtivas e relações simbólicas e identitárias com o rio São Francisco. O que possibilitou aos mediadores e quilombolas da Lapinha compreenderem o caráter relacional da identidade do grupo, e deslocá-la do campo conceitual para o politico, ou seja, as estratégias de negociação poderiam transitar tanto no espaço social do agrário como no campo ambiental.

Com o decorrer do processo de reintegração de posse, encaminhado pela FAREVASF, na Vara Agrária de Manga, ficou acordado que as famílias do Quilombo da Lapinha permaneceriam em uma área de 22 hectares, até que a ação transitasse em julgado.

Nesse ínterim, foi realizado, em 2007, na Serra do Ramalho, o II Encontro das Comunidades Vazanteiras. Evento em que a situação do encurralamento dos vazanteiros de Pau Preto se tornou mais tensa e a Reserva Extrativista (RESEX), observada no texto do SNUC (2000), emerge como estratégia política mais viável de garantir o vínculo e a permanência desta comunidade em seu território sobreposto pelo Parque Estadual Verde Grande. A urgência do IEF em resolver a situação da retirada dos vazanteiros de Pau Preto perdeu poder frente ao autoreconhecimento dos vazanteiros como "populações tradicionais" e a intervenção da promotoria das bacias do rio São Francisco e Verde Grande na mediação junto ao IEF. Surge daí a proposta de reconversão de parte do Parque Estadual Verde Grande em uma Unidade de Uso Sutentável.

Em 2007, foi encaminhado ao IEF o documento "Proposta em Debate: construção de uma Unidade de Conservação de Uso Sustentável dos vazanteiros de Pau Preto", que aliava áreas de conservação ao manejo agro-extrativista, incorporando técnicas de recuperação e manejo de sistemas agroflorestais. O parecer jurídico do IEF, emitido em setembro de 2008, com o título de RDS - Aspectos Jurídicos da Criação de Categoria de Manejo em Comunidade Vazanteira do Norte de Minas Gerais $^{10}$, propunha a substituição da proposta de RESEX pela de Reserva de Desenvolvimento Sustentável - RDS, ressaltando que, em tal categoria, "as populações devem residir 
na área da UC”, em contraposição à RESEX, que permite mais flexibilidade em relação a essa fixidez, considerando que "as populações podem ou não residir, mas devem utilizar a UC”. Caso que não se aplica aos vazanteiros que têm por constituição histórica e social a transumância como parte do sistema aberto de "direitos combinados"11, ou seja, direitos estabelecidos e regulados por eles mesmos, sem intervenção institucional. O que sempre possibilitou a eles a liberdade de ir e vir entre uma comunidade e outra, e gerir o direito sobre os territórios pela cessão de direitos a quem nele trabalha ou venda. Outra característica que faz parte da realidade de algumas poucas famílias vazanteiras é manter duas casas; uma em seus territórios e outra nos municípios de Matias Cardoso ou Manga, o que facilita um lugar em momentos de necessidade para se ter acesso a educação e saúde. De qualquer forma, observa-se pelo SNUC, que, tanto a demarcação do território como RDS ou RESEX criam uma situação de regulação externa sobre o modo de vida vazanteiro, em que seu poder de gestão sobre o território seria diminuído. Pois, em se tratando de uma Unidade de Uso Sustentável, independente da modalidade, esta seria gerenciada por um Conselho Deliberativo, presidido pelo IEF, órgão responsável por sua administração (SNUC, 2000, artigo 18 e 20). Entretanto, a RDS responderia aos anseios do referido instituto, uma vez que demarcaria uma área de proteção integral e fixaria os vazanteiros em lugares determinados, facilitando o controle, a fiscalização do "meio ambiente" e das ações dos vazanteiros sobre ele. Acertou-se junto à promotoria a mudança da modalidade de RESEX para RDS e, dentro dessa nova proposta, a necessidade de um novo estudo de ocupação e uso dos ambientes pelos vazanteiros com a colaboração da Universidade Estadual de Montes Claros (Unimontes) e do Instituto de Ciências Agrárias da UFMG/Montes Claros.

\section{De vazanteiros à irrigantes: o paradigma da modernização ecológica}

Nesse processo politico de negociação, o IEF reconheceu áreas degradadas no interior do parque, antes utilizadas intensivamente para agricultura irrigada e pastagem pelas empresas rurais (Fazenda Catelda e Fazenda Profaz), e "que não se prestam à conservação da biodiversidade"12. Logo,

[...] a contraproposta seria a aquisição da área dos pivôs das propriedades nos limites do parque e a desafetação das mesmas mediante compensa- ção por nova área com relevância ecológica, a qual pode ser agregada a qualquer uma das unidades de conservação do sistema de áreas protegidas do Jaíba. Por fim, viável seria a transferência da comunidade de Pau Preto para a área dos pivôs ${ }^{12}$.

Ao desconsiderar a relação dialética e identitária da comunidade de Pau Preto e a natureza, da qual dependem diretamente, o IEF adequa à perspectiva preservacionista uma contraproposta que desestrutura o modo de apropriação e produção social do ambiente realizada pelos vazanteiros sugerindo transformá-los em irrigantes. Atuam, ainda, na direção das políticas compensatórias propondo substituir a área degradada a ser repassada para os vazanteiros por outra de relevância ecológica.

O confronto entre visões de mundo e de projetos sociais entre o IEF e os vazanteiros, fez com que o primeiro questionasse o direito de autoidentificação dos vazanteiros, ressaltando que estes deveriam "estar indubitavelmente caracterizadas como tradicionais"10. Pois, "não há intenção de resolver problemas agrários que não estejam interligados a esse assunto ao criar-se uma RDS"10. Assim, as posições dos atores no campo ambiental revelam o lugar que ocupam nesse campo e como suas intervenções são orientadas pelas regras e critérios dos grupos e instituições às quais pertencem, o que fica evidente nas negociações.

Após esse período, outros encontros e reuniões foram promovidos em outras ilhas propiciando a participação de vários grupos vazanteiros em seminários, conferências e outros espaços sociais. Eventos que possibilitaram o fortalecimento e a politização desses grupos que, de "encurralados", foram se movimentando nas disputas do campo ambiental, baseados principalmente na articulação dos vazanteiros de Pau Preto, Pau de Légua e Quilombo da Lapinha.

\section{Encurralados, mas em movimento}

Em 2008 surgiu Pau de Légua, com o conflito lá da Mata Seca. Com isso, com essa articulação, em 2006 e 2007, da luta das comunidades em torno do Parque Verde Grande, do Parque da Mata Seca e em torno do Parque do Cajueiro, na Casa Grande, surge, então, esse segundo seminário da Ressaca, em setembro de 2008. Daí já tinha agora a representação de todas essas comunidades que estavam vivendo um conflito. Então, nesse seminário, a gente deu um impulso para a luta deles. Aí avançou. Dalí nós começamos a pensar as propostas que saíram de lá. Então marcamos com Pau de Légua, que acabou acontecendo outro seminário. E essa 
articulação vem fortalecendo os grupos. E já vamos subindo o rio, já estamos em Itacarambi. Aconteceu agora o encontro na Ilha do Capão, que reuniu as comunidades do Pau Preto a Itacarambi; tinham onze ilhas. Foi um momento em que comemoramos os 18 anos da Associação dos Vazanteiros de Itacarambi. E o próximo seminário vai ser na ilha do Jenipapo em outubro (Entrevista concedida por integrante da CPT, em agosto de 2009)4.

A movimentação foi se constituindo ao longo de toda a bacia do alto e médio São Francisco, entre diversos grupos vazanteiros que foram se articulando nesses anos e apoiando as comunidades de Pau Preto, Pau de Légua e Quilombo da Lapinha, uma vez que, a situação social de encurralamento desses grupos os colocava em maior risco de dissolução social.

Em setembro de 2008 realizou-se no Quilombo da Lapinha o "Encontro da Ilha da Ressaca", denominado Seminário Vazanteiros do São Francisco: entre os labirintos das leis ambientais e os direitos territoriais das populações tradicionais. Daí resultou a troca de experiências sobre territórios tradicionais regularizados no Amazonas, o debate com instituições públicas do campo agrário, ambiental e jurídico, e a produção do "mapa do encurralamento". Mapeamento que visibilizou a condição de atingidos de várias comunidades vazanteiras e ribeirinhas ali presentes, tanto por parques ambientais como por grandes fazendas agropecuárias. Em abril de 2009 realizou-se o IV Encontro dos Vazanteiros, na Ilha de Pau de Légua, com objetivo de fortalecer a articulação entre esses grupos e analisar o tensionamento das relações entre os vazanteiros de Pau de Légua e o gerente do Parque Estadual da Mata Seca (IEF), que buscava impor o cadastramento dos moradores da comunidade para retirá-los do local. Período acompanhado por uma série de situações repressivas como aplicação de multas, apreensão de material de trabalho e destruição de barracas com apoio da polícia militar. A gravidade do conflito reverberou junto à Comissão Especial de "Direitos Humanos e Alimentação Adequada", composta por representantes de diversos órgãos públicos federais, que estiveram presentes nas comunidades para verificar as violações junto a esses grupos sociais.

A entrada em cena da comissão agregou importante repercursão política sobre o órgão ambiental propiciando mudanças nas relações dos demais órgãos públicos com essas coletividades. Dentre os órgãos, a participação da Superintendência do Patrimônio da União (SPU) foi imprescindível para suspender as ações repressivas do IEF sobre os vazanteiros, uma vez que foi esclarecido que estes se encontravam em áreas da União e não do estado, além de tais áreas serem passíveis de doação às comunidades tradicionais vazanteiras, através de Termo de Autorização de Uso (TAU). Foi nessa ocasião que se tomou conhecimento da ilicitude das indenizações realizadas pelo Estado, através do IEF, na compra de fazendas para os parques localizados em áreas da União. A experiência de regularização das áreas ribeirinhas, realizadas pela SPU no Estado do Pará, trouxe conhecimento de portarias importantes a serem debatidas no caso dos vazanteiros. A primeira, no 284 , de 14 de outubro de 2005 , tinha como objetivo, conforme consta no artigo $1^{\circ}$ :

Disciplinar a utilização e o aproveitamento dos recursos naturais das várzeas, ribeirinhas de rios, sob o domínio da união, em favor das populações tradicionais através da concessão de autorização de uso para o desbaste de açaizais, colheita de frutos ou manejo de outras espécies extrativistas, a ser conferida, em caráter excepcional, transitório e precário, nas áreas sob o dominio da União, caracterizadas como várzea, ou presumíveis terrenos de marinha e acrescidos ${ }^{13}$.

Essa portaria avançou em termos de regularização fundiária naquela região, mas, por outro lado, se mostrou insuficiente diante da necessidade do reconhecimento da posse coletiva dos ribeirinhos e em relação ao tamanho da área: circunscrita a um raio de $500 \mathrm{~m}$ a partir de um ponto estabelecido no local de moradia do requerente. O regime de apropriação e uso comunal dos recursos naturais característicos dessas comunidades demandou a revogação da portaria $n^{\circ} 284$, de 14 de outubro de 2005, e sua substituição pela portaria $\mathrm{n}^{\circ} 100$, de 3 de junho de 2009. Esta última garantia a autorização de uso coletivo, acesso à aposentadoria, a recursos e programas sociais do governo federal, além da ampliação da área para 15 módulos fiscais.

Em portaria posterior, $n^{\circ} 173$, de 31 de agosto de 2009, a União delegou aos Superintendentes Estaduais do Patrimônio da União competência para exame e concessão da Autorização de Uso de que trata a portaria no 100 , de 3 de junho de 2009. Tal informação elevou o ânimo do movimento, que percebeu oportunidade concreta de reapropriação territorial, com o apoio da SPU, e maior poder de negociação com o IEF. Na visita da comissão, os vazanteiros de Pau de Légua entregaram a Carta-proposta de implementação da RDS de Pau de Légua, encaminhada anteriormente ao governo do estado de Minas Gerais, 
à Diretoria Geral e gerência do IEF e ao MPE. Documento que trazia denúncias das práticas repressivas do IEF junto à comunidade, e sobre o processo de assoreamento das lagoas e mortalidade de peixes, após a intervenção da instituição no local. Preocupação, que, de acordo com os vazanteiros, são resultado da proibição das práticas de manejo tradicionais desenvolvidas por eles, e que contribuiu durante gerações para a garantia da biodiversidade dos peixes e a preservação das lagoas. Nesse sentido, apontam a proposta da RDS como modalidade fundamental para preservação e conservação dos recursos naturais de seus territórios, aliada à manutenção cultural e social do grupo, como se lê em trecho abaixo:

Uma proposta que vai ajudar a preservar as lagoas, que vai ajudar na reprodução dos peixes, que vai ajudar os animais silvestres viverem. E que vai garantir o nosso sustento, o sustento de nossos filhos. E que vai manter a nossa cultura, o nosso jeito de viver. E que vai contribuir com a vida do São Francisco, vida que está dependendo muito de quem cuida dele melhor, porque o que vocês estão deixando fazer aí nas partes de cima do rio, é acabar mais depressa ainda com a vida dele ${ }^{14}$.

Tal documento traz a articulação entre "tradição” e técnicas agroecológicas como modelo de sustentabilidade em contraposição às práticas conservacionistas. Nesse sentido, buscam na agroecologia capital técnico reconhecido no campo ambiental para legitimar suas práticas e melhorá-las, apresentando-se, assim, como os sujeitos mais aptos a cuidarem da natureza.

[...] para viabilizar estas propostas já estamos fazendo diversas experiências. Já fizemos visitas de intercâmbio em áreas de assentamentos agroextrativistas, já estamos fazendo cursos de manejo agro-ecológico em áreas de cultivo, onde queremos suspender o uso eventual de agrotóxicos e proteger a mata ciliar com $S A F^{14}$

Logo após o evento da "missão vazanteira", uma série de contravenções realizadas pelo exdiretor regional do IEF, veio a público através de uma operação coordenada pelo MPE, denominada "Máfia Verde". Nessa conjuntura, o IEF era objeto de processo criminal que, além do ex-diretor, envolvia técnicos da instituição que estão sendo investigados por desvio de verbas, cancelamento ilegal de multas, infrações ambientais, apropriação de honorários, fraude em licitações, acordos judiciais irregulares e pagamento indevido. Dentre as contravenções, inclui-se o superfaturamento realizado em favor da empresa Agropecuária Catelda S.A., que teve sua sede desapropriada para a criação do Parque Estadual Verde Grande, sob o processo $n^{\circ}$. 0024.11.122276-6, da 2a Vara Criminal do Estado de Minas Gerais. Situação que fez o IEF retroceder nas relações autoritárias com os vazanteiros e tentar se reorganizar internamente.

Nos dias 16 e 17 de setembro de 2010 foi realizado o "V Encontro" do movimento, denominado de Vazanteiros em Movimento: povos das águas e terras crescentes. O local foi a Ilha do Jenipapo, território vazanteiro no município de Itacarambi (MG), e teve como objetivo a discussão de propostas sobre regularização dos territórios vazanteiros e a revitalização socioambiental do Vale do São Francisco. Encontro que reaproximou os Xacriabás (povo indígena da região), quilombolas e vazanteiros; grupos sociais com culturas diferenciadas, mas lutas semelhantes.

A presença do gerente regional da SPU, neste evento, ratificou que a maior parte dos territórios vazanteiros, é, de acordo com o artigo 20 da Constituição Federal de 1988, terrenos da União. Uma vez que, o rio São Francisco banha mais de um estado da federação, incluindo as águas, seus respectivos terrenos marginais, as praias e terrenos do seu domínio. A partir desta perspectiva ratificou a possibilidade do uso das TAU como forma de garantir a regularização fundiária dos vazanteiros de Pau Preto, Pau de Légua e Quilombo da Lapinha. Possibilidade que causou reação da promotoria da Bacia do rio São Francisco (MPE) em relação às APPs, que, orientada por uma visão conservacionista do ambiente, ressaltou que: não dá para fazer reforma agrária em margem, vazante e ilha do São Francisco. De acordo com a promotoria, o "zoneamento da SPU” talvez não atendesse a todos, insistindo na ideia de que o parque seria a saída mais viável, pois não dá para ser só uma beiradinha. Tem muita terra particular. Então, onde tem parque é bom. É mais fácil para resolver (depoimento coletado no V Encontro, 2010) 4 .

Entretanto, as negociações para a criação da RDS de Pau Preto não seguiram adiante, ou seja, não era algo tão fácil de se resolver como colocado pela promotoria, uma vez que, a ideia do parque enquanto espaço da conservação sem gente, incorporado pelo IEF impossibilitava compartilhar a possibilidade de conservar com gente, como proposto pelos vazanteiros desde 2007.

Assim, em uma ação coletiva coordenada, entre as comunidades de Pau Preto, Pau de Légua e Quilombo da Lapinha, os "Vazanteiros em Movimento”, no dia 24 de julho de 2011, como forma de retomar o território tradicional e pressionar estrategicamente o IEF em relação às negociações da RDS, deram início à autodemarcação da RDS 
de Pau Preto, na ex-sede da Fazenda Catelda. A repercussão da autodemarcação, estratégia já utilizada pelos geraizeiros na luta pela reapropriação territorial, possibilitou, em novembro do mesmo ano, um novo processo de renegociação da RDS de Pau Preto, com a presença no local da Coordenação das promotorias das bacias do rio São Francisco, o IEF, o representante da Comissão Nacional dos Povos e Comunidades Tradicionais do Norte de Minas, a CPT, o CAA e os "Vazanteiros em Movimento".

Entretanto, até o momento, as negociações da RDS de Pau Preto, que se encontravam mais formalizadas e melhor encaminhadas, continuam sem resolução. A proposta da RDS de Pau de Légua tão pouco é considerada pelo IEF, conforme diretor das áreas protegidas em audiência da Comissão Nacional dos Direitos Humanos e Alimentação Adequada, realizada em Brasília, em março de 2014. Enquanto isso, o laudo antropológico do Quilombo da Lapinha já foi concluído e está em processo junto ao INCRA. Desde, então, vazanteiros e vazanteiras vêm garantindo sua sobrevivência de forma precária, através de plantios coletivos em pequenas áreas de terra firme e vazantes, associados a experimentos de agroecologia em parceria com o CAA. A movimentação na beira do rio São Francisco, ainda é constante, através de encontros que contribuem para suas formações políticas e para o acesso aos direitos territoriais. Na perspectiva da justiça ambiental, as dimensões epistemológicas e políticas subjacentes a esses processos de mobilização, se encontram fortemente imbricadas, transformando populações atingidas em sujeitos de enfrentamento e de transformação da sociedade ${ }^{15}$ No caso dos vazanteiros, uma rede foi se constituindo e ampliando com a reunião de uma série de povos e comunidades tradicionais, que buscam atualmente a reapropriação territorial e representação política através da "Articulação Rosalino". Batizada com o nome do cacique Xacriabá Rosalino Gomes de Oliveira, assassinado por fazendeiros da região em 1987, tem nele inspiração de luta para os demais povos e comunidades tradicionais da região, como: geraizeiros, vazanteiros, catingueiros, veredeiros e quilombolas. Fenômeno social contemporâneo que vem se expandindo e apoiando politicamente as lutas territoriais ao longo do estado de Minas Gerais, incorporando outros povos e comunidades tradicionais da Serra do Espinhaço, como quilombolas e apanhadoras de flor sempre viva.

\section{Considerações finais}

A objetivação das comunidades vazanteiras de Pau Preto, Pau de Légua e Quilombo da Lapinha no "Vazanteiros em Movimento" expressa o que Almeida ${ }^{3}$ ressaltou como a combinação de um critério político-organizativo à uma "política de identidades". O que permitiu a essas coletividades, apoiadas sobre saberes específicos próprios de suas realidades, se agruparem sob uma mesma expressão coletiva. De um lado, o movimento trouxe uma complexidade de elementos identitários para o campo ambiental, e, por outro, possibilitou a esses grupos a interiorização de uma nova questão social e pública como: a conservação do ambiente e seus mecanismos institucionais de proteção da natureza. Nessa perspectiva, pode-se dizer que os "Vazanteiros em Movimento" ao se verem "encurralados pelos parques" foram se construindo a partir de um processo de "ambientalização"1 que os permitiu apropriarem-se do discurso e dos instrumentos jurídicos próprios desse campo, em busca da reapropriação de seus territórios tradicionais. Semelhantes aos movimentos por justiça ambiental, destaca-se nesse processo a dimensão da ação gerada pela consciência de que inúmeros problemas ambientais possuem sua origem em um modelo de desenvolvimento injusto, tal como apontado por diversos estudos relativos ao tema, particularmente grupos sociais étnicos e populações mais pobres e vulneráveis ${ }^{16}$. Cientes deste contexto, vazanteiros disputam, junto aos órgãos públicos ambientais, projetos alternativos de sustentabilidade e conservação da natureza, associados às suas tradições locais e visão de mundo.

Nesta dinâmica processual, houve reconhecimento de brechas existentes no próprio SNUC, que lhes possibilitou o reconhecimento e a afirmação do grupo como "populações tradicionais" e o entendimento do jogo que se joga no campo ambiental, o "jogo da mitigação" ${ }^{17}$. Jogo no qual as modalidades de reservas de usos sustentável, via RDS ou RESEX foram acionadas como estratégia política de reapropriação territorial.

Entretanto, o processo de reconversão das unidades de proteção integral para reservas de desenvolvimento sustentável, não se efetiva pela sustentação do IEF de uma visão de conservação dicotômica que orienta suas ações no campo ambiental. Por outro lado, a possibilidade da implementação de reservas de desenvolvimento sustentável, como estratégia de reapropriação ter- 
ritorial, sinaliza que tal proposta está longe de trazer de volta o "tempo de liberto", presente na memória das comunidades vazanteiras. Tempo que significou o livre acesso e autonomia no uso do território e que se opõe ao gerenciamento realizado pelo ICMBio, em âmbito nacional (exemplos da Amazônia e da Mata Atlântica) ou pelos Agentes Estaduais de Meio Ambiente (IEF), em âmbito estadual, em Unidades de Uso Sustentável.

Tal dificuldade processual de implementação das RDS tem criado a discussão no interior dos "Vazanteiros em Movimento", de que outras alternativas poderão ser discutidas e implementadas. Alternativas que procuram articular pro- dução agropecuária e conservação ambiental fora do âmbito do SNUC, porém no escopo da "proteção ambiental", como no caso de um assentamento agroextrativista. Desenha-se nesse processo uma nova divisão do trabalho político, face à questão ambiental, combinando ciência, movimentos militantes e um repertório de saberes específicos próprios das realidades localizadas, na acumulação de um capital de conhecimento. Nessa perspectiva, as lutas sociais de tais grupos são renovadas pela construção de uma nova ordem política e de um novo paradigma, convertendo-se em uma espécie de heterodoxia frente à doxa hegemônica do campo ambiental. 


\section{Referências}

1. Fundação Biodiversitas. Biodiversidade em Minas Gerais: um Atlas para sua Conservação. Belo Horizonte; 2005.

2. Lopes JSL. Sobre processos de ambientalização dos conflitos e sobre dilemas da participação. Horizontes Antropológicos 2006; 12(25):31-64.

3. Almeida AWB. Terra de quilombo, terras indígenas, "babaçuais livre", "castanhais do povo", faixinais e fundos de pasto: terras tradicionalmente ocupadas. Manaus: PGSCA - UFAM; 2008.

4. Anaya FC. De encurralados pelos parques a vazanteiros em movimento: as reivindicações territoriais das comunidades vazanteiras de Pau Preto, Pau de Légua e Quilombo da Lapinha no campo ambiental [tese]: Belo Horizonte: FAFICH-UFMG; 2012.

5. Scott J. Formas Cotidianas de resistência. Raízes 2000; 21(1):10-31.

6. Carta-Manifesto das Mulheres e Homens Vazanteiros. Ilha da Ingazeira, Maio de 2006.

7. Brasil. Lei no 9.985, de 18 de julho de 2000. Regulamenta o art. 225, $\$ 10$, incisos I, II, III e VII da Constituição Federal, institui o Sistema Nacional de Unidades de Conservação da Natureza e dá outras providências. Diário Oficial da União 2000; 19 jul.

8. Proposta de Assentamento Agroextrativista São Francisco: uma contribuição do Centro de agricultura Alternativa-NM e Comissão Pastoral da Terra aos vazanteiros da Ilha da Ressaca. Matias Cardoso; 2007.

9. Proposta em Debate: construção de uma unidade de conservação de uso sustentável dos vazanteiros de Pau Preto. 2007.

10. Silqueira IV. Reserva de Desenvolvimento Sustentável - RDS. Aspectos Jurídicos da criação de categoria de Manejo em Comunidade Vazanteira do Norte de Minas Gerais. Procuradoria regional do IEF, setembro de 2008. Documento encaminhado à Coordenadoria das Bacias dos Rios São Francisco, Verde Grande e Jequitinhonha (MPE-MG). Minas Gerais: Procuradoria regional do IEF; 2008.
11. Luz OC. Vazanteiros do Rio São Francisco: um estudo sobre populações tradicionais e territorialidade no Norte de Minas Gerais [dissertação]. Belo Horizonte: FAFICH-UFMG; 2005.

12. Silqueira IV, Costa CB. Situação Atual do Parque Estadual Verde grande. Propostas de criação da categoria de Manejo. Documentação Pertinente à Comunidade do Pau Preto. Parecer relatório Final. Encaminhado à Promotoria de Justiça do Rio São Francisco e Sub-bacia do rio Verde Grande-MG. Minas Gerais: Procuradoria regional do IEF; 2008.

13. Brasil. Portaria no 284, de 14 de outubro de 2005. Diário Oficial da União 2005; 17 out.

14. Carta-Proposta dos Vazanteiros e Vazanteiras da Ilha de Pau de Légua: povos das Águas e das Terras Crescentes do São Francisco. Belo Horizonte:[s.n.] ; 2010.

15. Porto MF, Finamore R. Riscos, Saúde e Justiça Ambiental: o protagonismo da populaces atingidas na produção de conhecimento. Cien Saude Colet 2012; 17(Supl. 6):1493-1501.

16. Porto MF. Saúde do trabalhador e o desafio ambiental: contribuições do enfoque ecossocial, da ecologia política e do movimento pela justiça ambiental. Cien Saude Colet 2005; 10(Supl. 4):829-839.

17. Carneiro EJ. Política Ambiental e a Ideologia do Desenvolvimento Sustentável. In: Zhouri A, Laschefski C, Pereira D, organizadores. A Insustentável Leveza da Política Ambiental: desenvolvimento e conflitos sócio-ambientais. Belo Horizonte: Autêntica; 2005. p. 27-48.

Artigo apresentado em 06/07/2014

Aprovado em 11/07/2014

Versão final apresentada em 12/07/2014 